\title{
CRITERIA FOR THE RECOGNITION OF SPECIES AND GENERA
}

\section{By C. Hart Merriam}

In systematic work among animals and plants one is continually confronted by the theoretical question: what shall constitute the grounds for the segregation of forms into subspecies, species, subgenera, genera, and higher groups; and by the practical question of drawing dividing lines between the groups recognized. And in examining series of closely related species from different localities, one is often confronted by specimens that differ from the previously known forms, so that it becomes necessary to ascertain whether the observed peculiarities are genuine characters or merely individual variations. If they are exhibited by several specimens and it is known that these specimens came from the same area, the inference is that they represent a form worthy of recognition by name. And if the differences are comparatively slight - not of sufficient importance to be accorded full specific rank-it is customary to assume the existence of intergrades and call the form a geographic race or subspecies.

Dividing lines are now drawn much finer than formerly, and in many cases it is difficult to make up one's mind whether to treat a particular form as a species or a subspecies. When this has been decided, the result is usually published and the matter dismissed. But the next time the author has occasion to discuss the group, he is likely to find that his viewpoint has changed, or that additional specimens give the case a different aspect, so that the status of the form as previously published requires readjustment. The author himself may make the change, but if not, some other writer may be counted on to do it for him. In other words, irrespective of the stability or worth of the form, its RANK is subject to change. This may be due to information afforded by additional material, or to an altered point of view on the part of the author-for we must remember that after all we ourselves are the scales on which zoological characters are weighed, and that unhappily we have no 'Bureau of Standards' to adjust the balances of our judgment.

For guidance in deciding whether a form shall be treated as a full species or a subspecies, two diametrically opposite methods have been advocated-one based on the presence or absence of intergrades, the other on the degree of differentiation of the form in question. While 
from the theoretical standpoint these methods are as far apart as possible, in practice they draw much nearer together. For in the great majority of cases of alleged intergradation the intergradation is assumed rather than proved, so that after all the student is influenced, albeit unconsciously, by the quantity of difference - this being in reality the determining factor in shaping his decision ss to whether or not intergradation exists.

But in studying animals and plants, what difference does it make, (a) whether the worker has before him actual intergrades, or (b) whether the relationship between forms is so close that he feels justified in assuming intergradation, or (c) whether in fact at the present moment of the world's history intergradation does or does not exist? For is it not clear that in the course of evolution, intergrades, if not now present, must have existed in the past, so that their remains are likely to turn up at any moment? And is it not equally clear that if we are to destroy species and genera because of the presence of intergrades, it is only a matter of time before the discovery of living forms or the accumulation of paleontological evidence will lead to the abolition of a large proportion of our species and genera?

To my mind, the criterion of intergradation is one of the most pernicious that has ever been introduced into the systematic study of animals and plants and one necessarily productive of an ever-changing nomenclature. And furthermore, it has often resulted in bringing together forms between which intergradation has not only not been proved, but which in many cases never existed-the forms in question having arisen from a common ancestry in the distant past, rather than from one another under existing conditions. And even in the case of forms presumably derived from one another under existing conditions, what difference does it make whether the specimens at hand prove intergradation, or whether the closeness of their interrelationship implies that one is an offshoot of the other? Is not the measure of relationship of more consequence than the accident of survival or non-survival of intergrades?

In practice, neither the criterion of intergradation nor that of degree of divergence can claim immunity from the mistakes that come from the study of inadequate material, nor from those due to the idiosyncrasies of the personal equation, for until the arrival of the biological millennium personal opinion is likely to govern the existence or nonexistence of intergrades and to stand in the way of agreement as to the measure of difference necessary to the recognition of species and genera. 
In the case of errors resulting from inadequate material-the hovering demon of the systematic worker-no prophylactic treatment has yet been discovered, though experience and judgment count for much in lessening the frequency and severity of incorrect conclusions.

The history of the progress of ornithology and mammalogy in America proves that by the criterion of intergradation many forms have been described as subspecies that later proved to be either independent species or offshoots of species other than those to which they were originally referred, showing that it is the practice of naturalists to ASsume intergradation rather than prove it. The truth of this may be demonstrated by an examination of the published records of specimens examined, for while actual intergrades are often at hand, the record shows that in the great majority of cases the author did not see specimens from intermediate localities - the only localities from which intergrades could possibly have come.

W. H. Osgood, in his monographic Revision of the Mice of the American genus Peromyscus, had before him the unparalleled collections of the United States Biological Survey, supplemented by those of various museums and individuals, amounting in all to upwards of 27,000 specimens. In studying this astounding wealth of material, covering practically all parts of the North American continent, he naturally found a large number of intergrades, in connection with which circumstance he says: "Until recent years continuous and perfect intergradation was demonstrable only in relatively few cases. And even now, although proved beyond doubt in group after group, in many cases it is merely taken for granted." (N. Am. Fauna No. 28, p. 17, April, 1909.)

More than twenty years ago, after serving for a number of years as a member of the A. O. U. Committee on Nomenclature and Classification of North American Birds, I was so impressed by the inconsistencies, shiftings of rank, and illogical conclusions necessitated by the intergradation rule that I published in Science the following protest and suggestion:

In practice it has been found that only in a small percentage of cases does an author have at his command a sufficiently large series of specimens, from a sufficient number of well-selected localities, to enable him to say positively that related forms do or do not intergrade. The result of this obvious embarrassment is that authors usually exercise their individual judgment as to the probable existence or non-existence of intergradation, thus introducing the personal equation it was hoped to avoid. . . . . It would seem therefore . . . . 
that it would serve a more useful purpose if the terms species and subspecies were so used as to indicate degree of difference, rather than the author's opinion as to the existence or non-existence of intergrades. . . . . In my judgment, forms which differ only slightly should rank as subspecies even if known not to intergrade, while forms which differ in definite, constant and easily recognized characters should rank as species even if known to intergrade.-Science, NS, V, pp. 753-758, May 14, 1897.

If the absence of intergrades in the hands of the student is the rule rather than the exception when dealing with mainland forms of presumably continuous distribution, what shall we say of closely related insular forms where the existence of intergrades is an obvious physical impossibility? And yet we all know that it is common practice-a practice in which I fully concur-to treat such forms as subspecies. Does not this demonstrate the absurdity of the intergradation rule? On the other hand, by adopting the criterion of degree of divergence, the imagination is not overtaxed, erroneous reference of subspecies to species from which they were not derived are rendered harmless, and the conclusions arrived at-usually the same as by the intergrade rule - may be stated without qualms of conscience.

To certain devotees of this rule, the discovery of intermediate forms seems to produce a psychologic shock, upsetting the judgment to such a degree that forms obviously entitled to recognition as full species are immediately degraded to the rank of subspecies.

The same is true of genera, for on the discovery of intermediate species, certain students feel impelled to bring together, under a single generic name, the members of two completely differentiated and easily recognizable genera.

And it may be added parenthetically that the same distorted point of view crops out here and there in the remote field of anthropology, some authors of distinction bringing together in a single linguistic family two or more strongly marked and perfectly distinct families because of the discovery (real or imagined) of an exceedingly remote ancestral relationship!

In these days of the universal acceptance of evolution, is it not bard to reconcile such reductions of groups with the facts that must be apparent to every one, for if species and genera and linguistic families are to be set aside because of the discovery of intermediate forms, does it not follow that sooner or later our classification is doomed to destruction, chaos taking the place of system? 


\section{$2 \mathrm{BHL}$ Biodiversity Heritage Library}

Merriam, C. Hart. 1919. "Criteria for the Recognition of Species and Genera." Journal of mammalogy 1, 6-9. https://doi.org/10.2307/1373714.

View This Item Online: https://www.biodiversitylibrary.org/item/220052

DOI: https://doi.org/10.2307/1373714

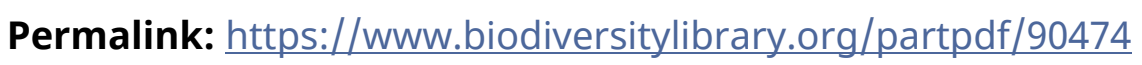

\section{Holding Institution}

Smithsonian Libraries

\section{Sponsored by}

Biodiversity Heritage Library

\section{Copyright \& Reuse}

Copyright Status: Not in copyright. The BHL knows of no copyright restrictions on this item.

This document was created from content at the Biodiversity Heritage Library, the world's largest open access digital library for biodiversity literature and archives. Visit BHL at https://www.biodiversitylibrary.org. 